\title{
Precipitated Calcium Carbonate Synthesis by Simultaneous Injection to Produce Nano Whisker Aragonite
}

\author{
Chilakala Ramakrishna, Thriveni Thenepalli*, Jae-Hoon Huh, and Ji Whan Ahn*; \\ Department of R\&D Team, Hanil Cement Corporation, Danyang 27003, Korea, \\ *Mineral Processing Division, Korea Institute of Geoscience and Mineral Resources, Daejeon 34132, Korea
}

(Received January 5, 2016; Revised January 22, 2016; Accepted January 25, 2016)

\begin{abstract}
The synthesis of pure calcium carbonate nanocrystals was achieved using a simultaneous injection method to produce nano particles of uniform size. These were characterized using scanning electron microscopy and powder X-ray diffraction. The nano particles were needle-shaped aragonite polymorphs, approximately $100-200 \mathrm{~nm}$ in length. The aragonite polymorph of calcium carbonate was prepared using aqueous solutions of $\mathrm{CaCl}_{2}$ and $\mathrm{Na}_{2} \mathrm{CO}_{3}$, which were injected simultaneously into double distilled water at $50^{\circ} \mathrm{C}$ and then allowed to react for $1.5 \mathrm{~h}$. The resulting whisker-type nano aragonite with high aspect ratio (30) is biocompatible and potentially suitable for applications in light weight plastics, as well as in the medical, pharmaceutical, cosmetic and paint industries.
\end{abstract}

Keywords : Nano aragonite whiskers, Simultaneous Injection Method, Aspect ratio, PCC

\section{Introduction}

C alcium carbonate $\left(\mathrm{CaCO}_{3}\right)$ is an abundant mineral in nature; making up about 5\% of the Earth's crust in the form of limestone. ${ }^{1}$ It is an important building material in living organisms (e.g., bones, teeth, and shells); moreover, it can be found in several industrial applications. Calcium carbonate is used as a coating pigment in paper, rubber, and adhesives; as filler in light weight plastics and concrete; for environmental pollution control and remediation in flue gas and water treatment; in fertilizers and animal feed as calcium supply; and in glass, ceramics, cosmetics, and hygienic products. $^{2)}$

In the past decades, calcium carbonate $\left(\mathrm{CaCO}_{3}\right)$ has attracted much attention due to its abundance in nature, and as an attractive model mineral for laboratory studies. ${ }^{3-5)}$ It is well known that there are three anhydrous crystalline phases of $\mathrm{CaCO}_{3}$ : calcite, aragonite, and vaterite. Calcite is thermodynamically the most stable, aragonite is metastable, and vaterite is the least stable and easily transforms into one of the other two phases. ${ }^{6}$ In practice, the stability of these polymorphic species depends mainly on temperature ${ }^{7-8)}$ However, the previous experiments were performed mainly at ambient temperatures.

The deposition of solid particles from the liquid phase through a precipitation reaction is a simple and reliable method for obtaining nanostructures with good control of

${ }^{\dagger}$ Corresponding author : Ji Whan Ahn

E-mail : ahnjw@kigam.re.kr

Tel : +82-42-868-3578 Fax : +82-42-861-3990 the particle characteristics. Several studies have been published regarding the synthesis of metal oxides, hydrous oxides, and hydroxide particles by precipitation from aqueous solutions. ${ }^{9-10)}$ In this study, the newly developed liquidliquid simultaneous injection method usually provides a mixture of polymorphs because of the three polymorphs (calcite, aragonite and vaterite). In order to induce the crystallization of aragonite (the high pressure polymorph) selectively, the precipitation conditions, such as temperature, $\mathrm{pH}$, feeding order, stirring, and reaction time must be carefully controlled.

In the present work, crystallization of $\mathrm{CaCO}_{3}$ at different temperatures, $\mathrm{pH}$, and different reaction times was investigated. Nano whisker-type aragonite of high aspect ratio was produced under various conditions. This study provides new understanding of the crystallization of $\mathrm{CaCO}_{3}$ in complex systems.

\section{Experimental Procedure}

The starting materials used in this study were $\mathrm{CaCl}_{2}$ and $\mathrm{Na}_{2} \mathrm{CO}_{3}$ (95 and 99\%, Junsei Company, Japan).

Nano aragonite whiskers was synthesized by simultaneous injection of $0.1 \mathrm{M}$ solutions of $\mathrm{CaCl}_{2}(1.5 \mathrm{~mL})$ and $\mathrm{Na}_{2}$. $\mathrm{CO}_{3}(1.5 \mathrm{~mL})$ into a glass reactor containing $10 \mathrm{~mL}$ of double-distilled water at a rate of $0.016 \mathrm{~mL} / \mathrm{min}$ and reaction temperature of $25-50^{\circ} \mathrm{C}$. In the experimental process a magnetic stirrer was used to agitate the reaction medium in a glass reactor. The primary reactant solutions $\mathrm{CaCl}_{2}$ and $\mathrm{Na}_{2} \mathrm{CO}_{3}$ were simultaneously injected into the reactor. The precipitate was aged for $0.5-1.5 \mathrm{~h}$, then filtered and dried at $80^{\circ} \mathrm{C}$ for $12 \mathrm{~h}$, as shown in Fig. 1 . The resulting product 


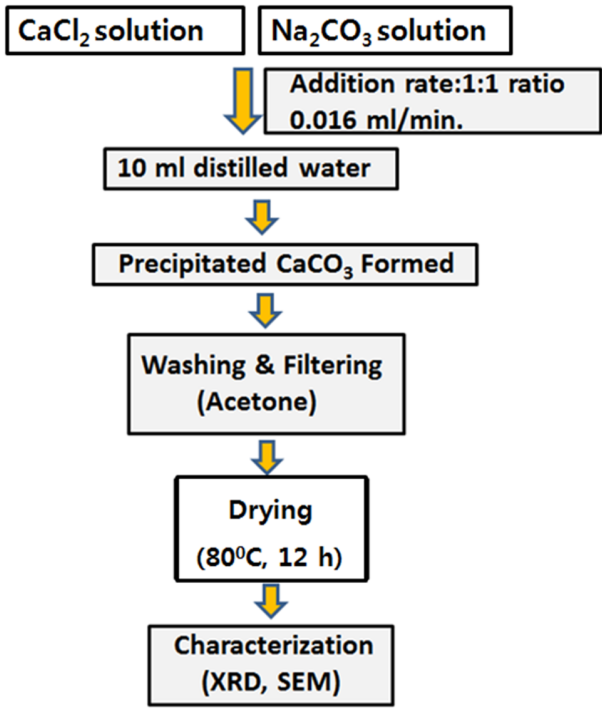

Fig. 1. Nano aragonite whiskers were synthesized by simultaneous injection.

was nano aragonite whiskers. The general mechanism involved in the $\mathrm{Na}_{2} \mathrm{CO}_{3}$ and $\mathrm{CaCl}_{2}$ reactions can be expressed as follows:

$$
\begin{aligned}
& \mathrm{CaCl}_{2}+\mathrm{Na}_{2} \mathrm{CO}_{3} \rightarrow \mathrm{CaCO}_{3}+2 \mathrm{NaCl} \\
& \text { Reaction } \mathrm{Mechanism:} \\
& \mathrm{CaCl}_{2} \rightarrow \mathrm{Ca}^{2+}+2 \mathrm{Cl}^{-} \\
& \mathrm{Na}_{2} \mathrm{CO}_{3} \rightarrow \mathrm{Na}^{2+}+\mathrm{CO}_{3}{ }^{2-} \\
& \mathrm{Ca}^{2+}+\mathrm{CO}_{3}{ }^{2-} \rightarrow \mathrm{CaCO}_{3}
\end{aligned}
$$

Supersaturation $\left(S_{I}\right)$ of the solution with respect to calcium carbonate,

$$
S_{I}=\frac{\left(\mathrm{Ca}^{2+}\right)\left(\mathrm{CO}_{3}^{2}\right)}{K_{s p}}>1
$$

where $\left(\mathrm{Ca}^{2+}\right)$ and $\left(\mathrm{CO}_{3}^{2-}\right)$ are the activities of calcium and carbonate ions in the solution, respectively, and $\mathrm{K}_{\mathrm{sp}}$ is the thermodynamic solubility of the aragonite product.

$$
\begin{aligned}
& \mathrm{Ca}^{2+}+\mathrm{CO}_{3}{ }^{2-} \rightarrow \mathrm{CaCO}_{3} \text { (nuclei) } \\
& \mathrm{CaCO}_{3}(\text { nuclei }) \rightarrow \mathrm{CaCO}_{3} \text { (Aragonite) }
\end{aligned}
$$

During the solution process experiments, metastable crystalline forms of $\mathrm{CaCO}_{3}$ such as vaterite were not identified in the X-ray diffraction spectra.

\section{Results and Discussion}

The initial concentration of calcium ions plays an important role in the synthesis of nano aragonite whiskers by the simultaneous injection method, at different temperatures.

\subsection{Effects of temperature}

Temperature is a key factor in the formation of aragonite whiskers. It is important to point out that a small difference in reaction temperature can result in dramatic changes in the crystal phase while other parameters are kept constant. A hydrothermal hot processing technique was developed to solidify the aragonite form of calcium carbonate; therefore, its application as solid material was increased. ${ }^{11)}$ Temperature and aging time affects the formation of polymorphs. Some researchers reported the addition of calcium nitrate and sodium carbonate without controlling the $\mathrm{pH}$, calcium carbonate was formed by indirect precipitation. The composition and high fraction of aragonite was dependent on the temperature $>50^{\circ} \mathrm{C}$, with digestion time of $0.1 \mathrm{~h}^{12)}$

Many researchers have investigated the effects of temperature on the formation of aragonite whiskers/needles. ${ }^{13-}$ ${ }^{24)}$ Different types of aragonite crystals were synthesized by combining aqueous solutions of $\mathrm{Na}_{2} \mathrm{CO}_{3}$ and $\mathrm{CaCl}_{2}$ under ambient reaction conditions. A plausible mechanism was proposed for the formation of aragonite based on the phase transformation behavior of calcium carbonate during synthesis. This preparation technique involved simultaneous injection of aqueous solutions of $\mathrm{Na}_{2} \mathrm{CO}_{3}$ and $\mathrm{CaCl}_{2}$ at different temperatures without any additives. This led to the formation of aragonite with different shapes. From these results, it was seen that three reaction parameters showed significant effect on the morphology of particles in the aragonite phase namely (i) the temperature of the reaction, (ii) the reaction time, and (iii) the effect of $\mathrm{pH}$. These aragonite crystals were found to be stable in solid states for a long time. ${ }^{25)}$

The present work revealed that nano aragonite whiskers were synthesized by combining $\mathrm{Na}_{2} \mathrm{CO}_{3}$ and $\mathrm{CaCl}_{2}$ solutions injected (1:1 ratio) into distilled water (liquid-liquid reaction) at different temperatures $\left(25,30,40\right.$ and $\left.50^{\circ} \mathrm{C}\right)$. That pure uniform nano aragonite needles (100-200 nm) were synthesized with high aspect ratio (30) at $50^{\circ} \mathrm{C}$, is clearly observed from the XRD analysis (Fig. 2) and scanning electron microscope images. Fig. 3 shows the morphology of nano whisker aragonite. By decreasing the temperature to 40,30 , and $25^{\circ} \mathrm{C}$, a mixture of aragonite and calcite phases

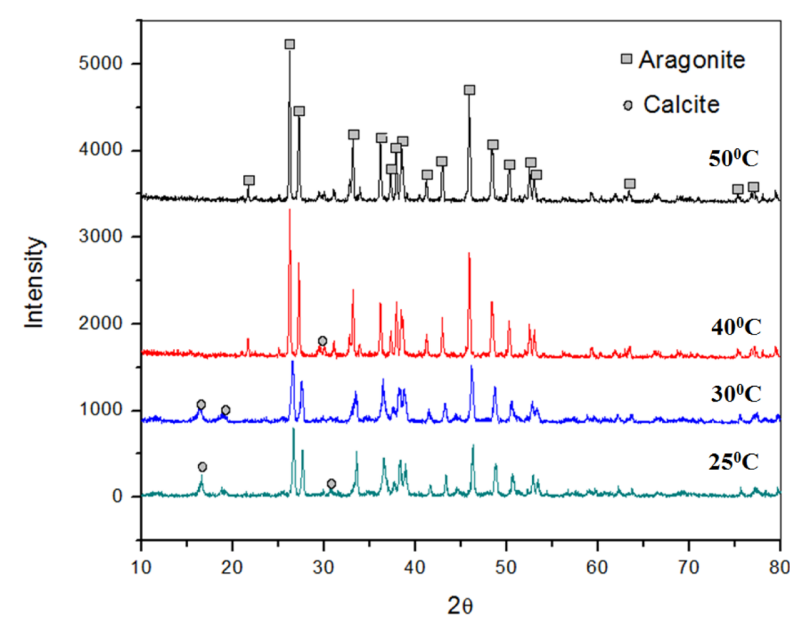

Fig. 2. XRD analysis of nano aragonite whiskers at different temperatures $\left(25,30,40\right.$, and $\left.50^{\circ} \mathrm{C}\right)$. 

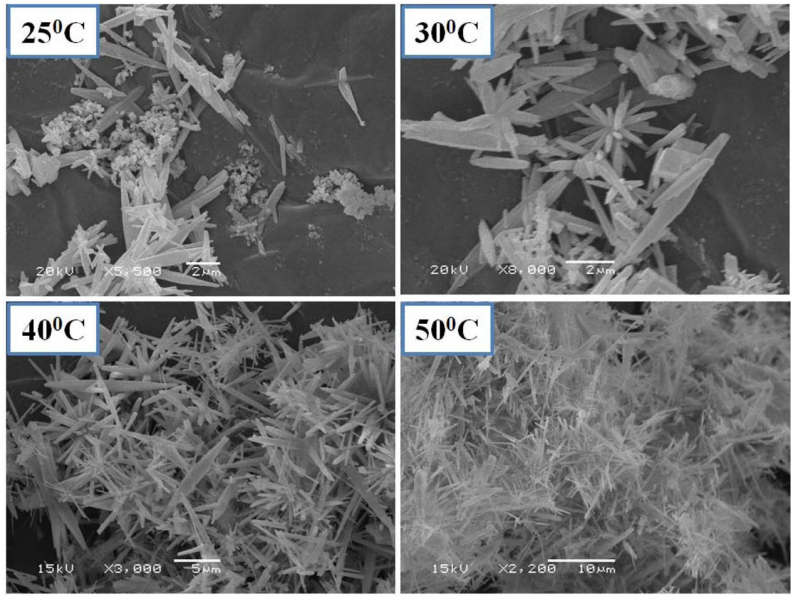

Fig. 3. Effect of different temperatures on the morphology of nano aragonite whiskers, revealed by scanning electron microscopy $\left(25,30,40\right.$, and $\left.50^{\circ} \mathrm{C}\right)$.

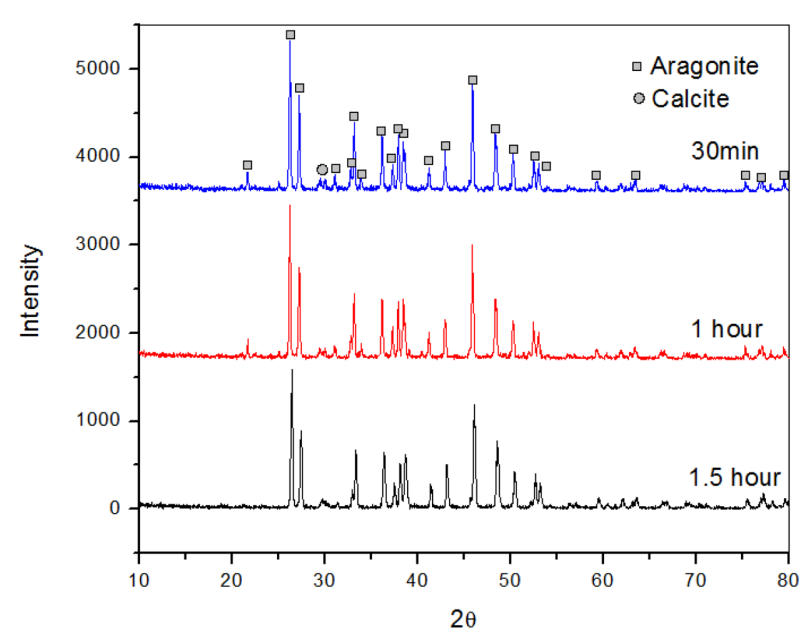

Fig. 4. XRD analysis of nano aragonite whiskers at different durations of reaction time $(0.5,1.0$, and $1.5 \mathrm{~h})$.
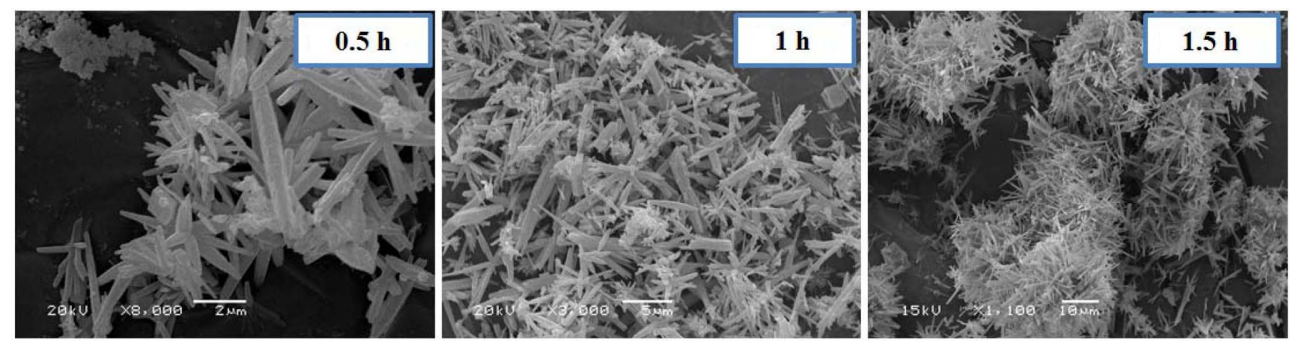

Fig. 5. Effect of different reaction time durations on the morphology of nano aragonite whiskers, revealed by scanning electron microscopy $(0.5,1.0$, and $1.5 \mathrm{~h})$.

were obtained. Based on the experimental results, the reaction temperature for each of the $\mathrm{CaCO}_{3}$ polymorphs should play a key role in determining which of the polymorphs of $\mathrm{CaCO}_{3}$ is formed.

\subsection{Effect of reaction time}

Time also plays a key role in the formation of aragonite whiskers. In the present study, to analyze the different effects of time on the simultaneous injection process, we observed the synthesis of whisker-type nano aragonite while injecting $\mathrm{Na}_{2} \mathrm{CO}_{3}$ and $\mathrm{CaCl}_{2}$ into aqueous solution at $50^{\circ} \mathrm{C}$, with different duration of reaction $(0.5,1.0$, or $1.5 \mathrm{~h})$. We obtained pure nano aragonite whiskers with $1.5 \mathrm{~h}$ reaction time by the solution process, which was confirmed by the XRD results (Fig. 4) and scanning electron microscopy (SEM) images. Fig. 5 shows the morphology of the nano aragonite whiskers.

The reaction times of 0.5 and $1.0 \mathrm{~h}$ after simultaneous injection produced a mixture of aragonite and calcite phases. Based on the experimental results, the calcite phase transformed into aragonite when the reaction time was extended to $1.5 \mathrm{~h}$, the reaction time of $\mathrm{CaCO}_{3}$ polymorphs should play a key role in the simultaneous injection process.

\subsection{Effect of $p H$}

The $\mathrm{pH}$ of the reaction solution is an important factor in

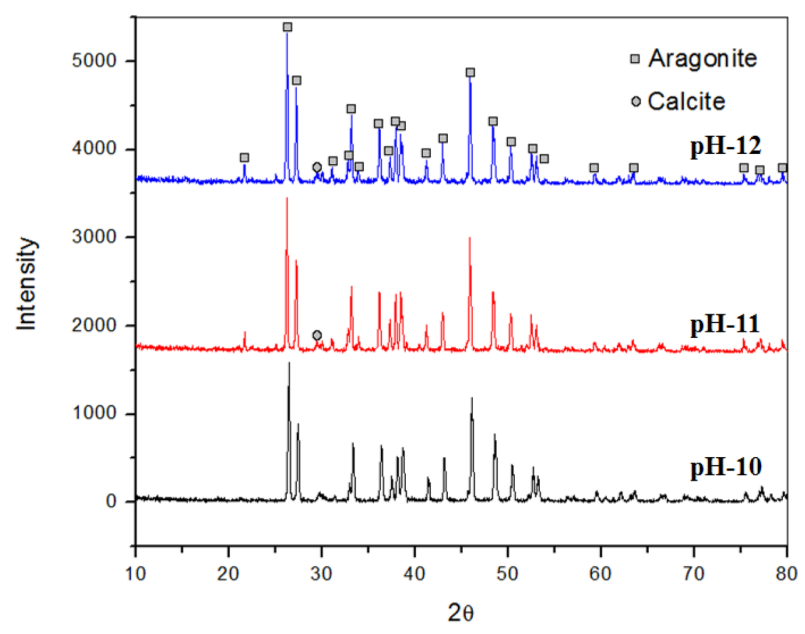

Fig. 6. XRD analysis of nano aragonite whiskers at different $\mathrm{pH}(10,11$, and 12).

the formation of the desired phase of aragonite. Pure aragonite was obtained at $\mathrm{pH} 10$; when the $\mathrm{pH}$ was greater than 12, calcite was obtained. ${ }^{26}$ From the parametric variation study on the synthesis of aragonite, it was concluded that $\mathrm{pH}<11$ at $\sim 7^{\circ} \mathrm{C}$, supported the formation of calcite and aragonite, but that nearly pure aragonite was obtained at $58^{\circ} \mathrm{C}$ with $\mathrm{pH}<10 .^{27)}$ Highly oriented aragonite particles 

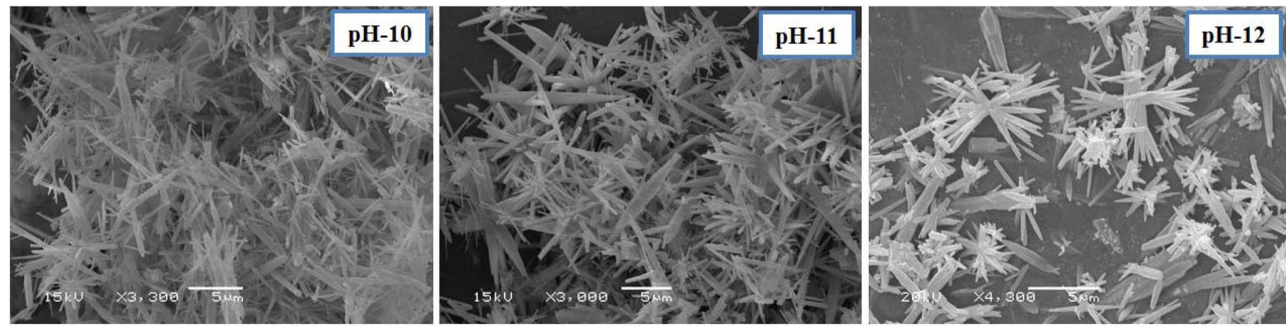

Fig. 7. Effect of different $\mathrm{pH}(10,11$, and 12) on the morphology of nano aragonite whiskers, revealed by scanning electron microscopy.

were found in the nacre layers of mollusk shell, and recently, aragonite rods were also obtained at $\mathrm{pH}$ ranging from 1.5 to 6.9 , without bio or organic macromolecules. ${ }^{28)}$

The results from the present study revealed that nano aragonite whiskers were synthesized by combining of $\mathrm{Na}_{2}$ $\mathrm{CO}_{3}$ and $\mathrm{CaCl}_{2}$ solutions injected simultaneously (1:1 ratio) into distilled water (liquid-liquid reaction) at different $\mathrm{pH}$ (10, 11, or 12). Pure uniform nano aragonite needles (100 $200 \mathrm{~nm}$ ) were synthesized with high aspect ratio (30) at $\mathrm{pH}$ 10 , which is clearly observable from XRD data shown in Fig. 6, and Fig. 7 shows the morphology of nano whisker aragonite in scanning electron microscopy images. By increasing the $\mathrm{pH}$ from 11 to 12 , a mixture of aragonite and calcite phases was obtained. Based on the experimental results, $\mathrm{pH} 10$ is most suitable for synthesis of pure aragonite whiskers.

\subsection{Applications}

Calcium carbonate $\left(\mathrm{CaCO}_{3}\right)$ is one of the most popular mineral fillers used in the plastics industry. It is widely available around the world, easy to grind or reduce to a specific particle size, compatible with a wide range of polymer resins, and economical. As an additive in plastic compounds, $\mathrm{CaCO}_{3}$ helps decrease surface energy and provides opacity and surface gloss, which improves the surface finish. In addition, when the particle size is carefully controlled, $\mathrm{CaCO}_{3}$ helps increase both impact strength and flexural modulus (stiffness). ${ }^{29)}$

\section{Conclusions}

The production of nano particulate, precipitated calcium carbonate (PCC), by simultaneous injection was performed in a glass reactor chamber. The simultaneous injection method was demonstrated with a chosen range of process parameters (temperature, reaction time, and $\mathrm{pH}$ ). From these, aragonite particles/crystals with different characteristic morphologies were produced. Because of the large number of physico-chemical processes, taking place during the $\mathrm{CaCl}_{2}$ and $\mathrm{Na}_{2} \mathrm{CO}_{3}$ reactions (dissolution and homogeneous nucleation of $\mathrm{CaCO}_{3}$ ), it is difficult to precisely predict the PCC properties. A large number of experiments are needed in order to obtain a product with exactly the desired properties. Therefore, an empirical approach based on experimental design techniques was employed to identify the effects of the chosen process parameters on the PCC morphology (specific shape of calcium carbonate).

A multiple experimental analysis of the obtained data suggests that temperature, reaction time, and $\mathrm{pH}$ play key roles in determining the nano PCC morphology. At lower temperatures, calcite can be produced, whereas higher temperature is suitable for obtaining nano aragonite PCC. These results emphasize the role of the liquid-liquid phase interface on the physical chemical properties of nano precipitated calcium carbonate.

Finally, this study demonstrated that the temperature, reaction time, and $\mathrm{pH}$ have significant effects on the average particle size, on precipitation, and on the morphology of the calcium carbonate crystals produced. Facile synthesis of nano aragonite whiskers was possible by liquid-liquid reaction using simultaneous injection. This process was used to control the experimental parameters to produce particles of average size from $100-200 \mathrm{~nm}$. The use of the aragonite form of precipitated calcium carbonate as a functional mineral filler for polypropylene is now growing. This is mainly due to its whisker/needle like morphology (similar to the shape of wollastonite needles). The results presented here demonstrate that nano aragonite crystals with strong potential for industrial applications, including as filler for light weight plastics in motor industries and paper industries, could be synthesized by simultaneous injection solution process under optimized conditions. The major advantage of this proposed method for obtaining nano aragonite needles is that it consumes less energy and offers cost benefits, being free of additives and not requiring template systems.

\section{Acknowledgments}

The authors are very grateful to the Korea Institute of Energy Technology Evaluation and Planning through the ETI program (Ministry of Trade, Industry, and Energy: Project No. 2013T100100021) for financial support of this research.

\section{REFERENCES}

1. C. W. Stearn and R. L. Carroll, Paleontology - The Record of Life; John Wiley \& Sons; New York, 1989.

2. CCA Europe, Mineral applications. http://www.cca-europe. 
eu/mineral-applications.html. Accessed on 07/13/2011.

3. L. M. Qi, J. Li, and J. M. Ma, "Biomimetic Morphogenesis of Calcium Carbonate in Mixed Solutions of Surfactants and Double-Hydrophilic Block Copolymers," Adv. Mater., 14 [4] 300-3 (2002).

4. R. J. Qi and Y. J. Zhu, "Microwave-Assisted Synthesis of Calcium Carbonate (Vaterite) of Various Morphologies in Water-Ethylene Glycol Mixed Solvents," J. Phys. Chem., 110 [16] 8302-6 (2006).

5. Y. Politi, Y. Levi-Kalisman, S. Raz, F. Wilt, L. Addadi, S. Weiner, and I. Sagi, "Structural Characterization of the Transient Amorphous Calcium Carbonate Precursor Phase in Sea Urchin Embryos," Adv. Funct. Mater., 16 [10] 128998 (2006).

6. S. F. Chen, S. H. Yu, J. Jiang, F. Q. Li, and Y. K. Liu, "Polymorph Discrimination of $\mathrm{CaCO}_{3}$ Mineral in an Ethanol/Water Solution: Formation of Complex Vaterite Superstructures and Aragonite Rods," Chem. Mater., 18 [1] 11522 (2006).

7. L. F. Wang, I. Sondi, and E. Matijevic, "Preparation of Uniform Needle-like Aragonite Particles by Homogeneous Precipitation," J. Colloid Interface Sci., 218 [2] 545-53 (1999).

8. M. Vučak, J. Perić, M. N. Pons, and S. Chanel, "Morphological Development in Calcium Carbonate Precipitation by the Ethanolamine Process," Powder Technol., 101 [1] 1-6 (1999).

9. J. E. Rodriguez-Paez, A. C. Caballero, M. Villegas, C. Moure, P. Duran, and J. F. Fernandez, "Controlled Precipitation Methods: Formation Mechanism of $\mathrm{ZnO}$ Nanoparticles," J. Eur. Ceram. Soc., 21 [7] 925-30 (2001).

10. P. D. Southon, J. R. Bartlett, J. L. Woolfrey, and B. BenNissan, "Formation and Characterization of an Aqueous Zirconium Hydroxide Colloid," Chem. Mater., 14 [10] 431319 (2002).

11. N. Yamasaki, T. Weiping, H. Lei, and K. Hosoi, "Solidification of Aragonite-Type $\mathrm{CaCO}_{3}$ Powder Containing Chitosan with Acetic Acid by Hydrothermal Hot Pressing," J. Mater. Sci. Lett., 14 [24] 1751-53 (1955).

12. J. L. Wary and F. Daniels, "Precipitation of Calcite and Aragonite," J. Am. Chem. Soc., 79 [9] 2031-34 (1957).

13. Y. Ota, N. Goto, I. Motoyama, T. Iwashita, and K. Nomura, "Process of Producing Needle-Shaped Calcium Carbonate Particles," US Patent 4,824,654 (April 25, 1989).

14. S. D. Skapin and I. Sondi, "Synthesis and Characterization of Calcite and Aragonite in Polyol Liquids: Control over Structure and Morphology," J. Colloid Interface Sci., 347 [2] 221-26 (2010).

15. W. Shang, Q. Liu, and S. Chen, "Synthesis of Aragonite Whiskers Using Gas-Liquid System," J. Xi'an Jiao. Univ., 33 10-7 (1999).

16. E. He, W. Shang, and S. Chen, "Effects of Phosphate Ion on the Growth of Aragonite Whisker in Heterogeneous Precip- itation from Suspension of $\mathrm{Ca}(\mathrm{OH})_{2}$," Rare Metal. Mat. Eng., 29 398-405 (2000).

17. Z. S. Hu and Y. L. Deng, "Supersaturation Control in Aragonite Synthesis Using Sparingly Dissoluble Calcium Salts as Reactants," J. Colloid Interface Sci., 266 [2] 359-65 (2003).

18. D. Rautaray, A. Banpurkar, S. R. Sainkar, A. V. Limaye, N. R. Pavaskar, S. B. Ogale, and M. Sastry, "Room-Temperature Synthesis of Aragonite Crystals at an Expanding Liquid-Liquid Interface in a Radial Hele-Shaw Cell," Adv. Mater., 15 [15] 1273-78 (2003).

19. C. Y. Tai and F. B. Chen, "Polymorphism of $\mathrm{CaCO}_{3}$ Precipitated in a Constant-Composition Environment," Amer. Inst. Chem. Eng. J., 44 [8] 1790-98 (1998).

20. P. Fellner, J. Jurišová, and L. Pach, "Preparation of Needle-like Aragonite Particles from Calcium Nitrate Solution," Acta Chim Slov., 4 [2] 3-10 (2011).

21. P. Fellner, J. Jurišová, J. Kozánková, and L. Pach, "Preparation of Needle-like Aragonite Particles from Calcium Nitrate Solution in Batch and Flow Reactors," Acta Chim Slov., 5 [1] 5-11 (2012).

22. R. Beck and J. P. Andreassen, "Influence of Crystallization Conditions on Crystal Morphology and Size of $\mathrm{CaCO}_{3}$ and their Effect on Pressure Filtration," AICHE J., 58 [1] 10721 (2012).

23. J. Jiang, Y. Zhang, X. Yang, X. He, X. Tang, and J. Liu, "Assemblage of Nano-Calcium Carbonate Particles on Palmitic Acid Template," Adv. Powder Technol., 25 [2] 615-20 (2014).

24. S. M. El-Sheikh, S. El-Sherbiny, A. Barhoum, and Y. Deng, "Effects of Cationic Surfactant during the Precipitation of Calcium Carbonate Nano-Particles on their Size, Morphology, and other Characteristics," Colloids and Surface. A: Physicochem. Eng. Aspects., 422 44-9 (2013).

25. D. Chakrabarty and S. Mahapatra, "Aragonite Crystals with Unconventional Morphologies," J. Mater. Chem., 9 [11] 2953-57 (1999).

26. L. D. Swinney, J. D. Stevens and R. W. Peters, "Calcium Carbonate Crystallization Kinetics," Indus. Eng. Chem. Fundamentals., 21 [1] 31-6 (1982).

27. C. F. Tai and F. B. Chen, "Polymorphism of $\mathrm{CaCO}_{3}$ Precipitated in a Constant-Composition Environment," Amer. Inst. Chem. Eng. J., 44 [8] 1790-98 (1998).

28. G. T. Zhou, Q. Z. Yao, J. Ni, and G. Jin, "Formation of Aragonite Mesocrystals and Implication for Biomineralization," Am. Mineral., 94 [2-3] 293-302 (2009).

29. T. Thriveni, Y. J. Ahn, C. Han, C. H. Ramakrishna, and J. W. Ahn, "A Strategy of Precipitated Calcium Carbonate $\left(\mathrm{CaCO}_{3}\right)$ Fillers for Enhancing the Mechanical Properties of Polypropylene Polymers," Korean J. Chem. Eng., 32 [6] 1009-22 (2015). 